\title{
BMJ Global Health Crossing borders: the PACK experience of spreading a complex health system intervention across low-income and middle-income countries
}

Ruth Cornick, ${ }^{1}$ Camilla Wattrus, ${ }^{1}$ Tracy Eastman, ${ }^{1}$ Christy Joy Ras, ${ }^{1}$ Ajibola Awotiwon, ${ }^{1}$ Lauren Anderson, ${ }^{1}$ Eric Bateman, ${ }^{1}$ Jorge Zepeda, ${ }^{2}$ Merrick Zwarenstein, ${ }^{3}$ Tanya Doherty, ${ }^{4}$ Lara Fairall ${ }^{1}$

To cite: Cornick R, Wattrus $\mathrm{C}$, Eastman T, et al. Crossing borders: the PACK experience of spreading a complex health system intervention across low-income and middle-income countries. BMJ Glob Health 2018;3:e001088. doi:10.1136/ bmjgh-2018-001088

Handling editor Seye Abimbola

Received 1 August 2018 Revised 14 September 2018 Accepted 14 September 2018

Check for updates

(c) Author(s) (or their employer(s)) 2018. Re-use permitted under CC BY-NC. No commercial re-use. See rights and permissions. Published by BMJ.

${ }^{1}$ Knowledge Translation Unit, University of Cape Town Lung Institute, Cape Town, South Africa

${ }^{2}$ Leeds Institute of Health Sciences, University of Leeds, Leeds, UK

${ }^{3}$ Western University, Centre for Studies in Family Medicine, Schulich School of Medicine \& Dentistry, London, Ontario, Canada

${ }^{4}$ South African Medical Research Council and Knowledge Translation Unit, University of Cape Town Lung Institute, Cape Town, South Africa

Correspondence to Dr Ruth Cornick; ruth.cornick@uct.ac.za

\section{ABSTRACT}

Developing a health system intervention that helps to improve primary care in a low-income and middleincome country (LMIC) is a considerable challenge; finding ways to spread that intervention to other LMICs is another. The Practical Approach to Care Kit (PACK) programme is a complex health system intervention that has been developed and adopted as policy in South Africa to improve and standardise primary care delivery. We have successfully spread PACK to several other LMICs, including Botswana, Brazil, Nigeria and Ethiopia. This paper describes our experiences of localising and implementing PACK in these countries, and our evolving mentorship model of localisation that entails our unit providing mentorship support to an in-country team to ensure that the programme is tailored to local resource constraints, burden of disease and on-the-ground realities. The iterative nature of the model's development meant that with each country experience, we could refine both the mentorship package and the programme itself with lessons from one country applied to the next-a 'learning health system' with global reach. While not yet formally evaluated, we appear to have created a feasible model for taking our health system intervention across more borders.

\section{SPREADING A COMPLEX HEALTH SYSTEM INTERVENTION}

Finding health system interventions that sustainably improve the quality and outcomes of care in low-income and middle-income countries (LMICs) is not easy, but there are some examples: 'promising practices' showcased by the Primary Health Care Performance Initiative $^{1}$ and notably, WHO strategies Integrated Management of Childhood Illness, ${ }^{2}$ Mental Health Gap Action Programme (mhGAP) ${ }^{3}$ and Practical Approach to Lung Health (PAL). ${ }^{4}$ The WHO interventions focus on delivering applicable and evidence-based clinical guidance to primary care providers in LMICs. Developing and successfully

\section{Summary box}

- Frameworks exist to guide localisation, and scale up of knowledge translation interventions focussed on specific conditions or a narrow range of clinical practices.

- But there is little describing how to spread comprehensive health service delivery programmes across borders to different low-income and middle-income country (LMIC) health systems.

- We have developed an acceptable and seemingly viable model for spreading our comprehensive clinical decision support programme, Practical Approach to Care Kit (PACK), in LMICs and have implemented it in several countries, including Botswana, Brazil, Nigeria and Ethiopia.

- A mentorship model to support in-country programme localisation and implementation achieved local ownership and successful piloting and is sustainable within the restricted resources of our unit.

- Vital for this success were regarding localisation of clinical decision support as the first step in programme implementation and drawing in key stakeholders throughout.

implementing such interventions is one, not inconsiderable, achievement, but the ability to spread a successful health system intervention to other settings is another challenge.$^{5-7}$

The knowledge translation and implementation science community has developed processes and frameworks that promote standardised, transparent strategies for adapting clinical guidance, ${ }^{8-11}$ even coining the term 'adolopment' ${ }^{12}$ - the combination of the adoption, adaption and de novo development required to tailor evidence-based clinical guidance to another setting. However, these frameworks are generally used to implement single disease guidelines but not for adapting comprehensive and integrated clinical guides 
that address all presenting illnesses and the multimorbidity increasingly encountered in LMIC primary care. ${ }^{13}$

Research and strategies ${ }^{14}$ addressing the spread of health systems interventions use various terms: 'diffusion' describes passive spread of an innovation, 'dissemination' the active and planned efforts to encourage target groups to adopt an innovation and 'scale-up' the widespread use among target populations. ${ }^{15}$ The latter can refer to the expansion of an intervention within one country or across borders at global scale.

This paper describes our experiences of disseminating a complex health system intervention to eight LMIC settings. We do not describe the direct implementation of the intervention, but rather the approach we use to spread the intervention to other countries. As far as we are aware, there is no published literature for this "upstream" implementation. We share the challenges and lessons that have informed the development of a feasible and reproducible approach for taking our health system innovation across borders.

\section{THE PRACTICAL APPROACH TO CARE KIT (PACK)}

The PACK programme aims to support primary care health workers in LMICs reorganise the care they deliver so that it speaks to the needs of their growing patient load. Expanded from a South African version of PAL that tackled respiratory conditions and HIV, (Practical Approach to Lung Health and HIV/AIDS in South Africa, PALSA PLUS), PACK was developed by a small team of health systems researchers, content developers and training programme designers at the Knowledge Translation Unit (KTU) in Cape Town, South Africa. The principles of the programme are that it be comprehensive, evidence informed and policy aligned and speak to the needs of end-users. ${ }^{16}$ It comprises the delivery of comprehensive clinical decision support for adult care, the PACK Adult guide, using an evidence-informed implementation programme. ${ }^{17}$ Key to its implementation is that PACK is localised-locally tailored and addressing health systems issues like health worker scope of practice, referral pathways and resource availability. Now adopted by government to support national primary care initiatives in South Africa, ${ }^{18}$ the programme has been developed, implemented and evaluated over almost 20 years and mixed methods evaluations, including pragmatic randomised trials, have shown multiple modest, consistent and reproducible improvements in quality of care, health outcomes and clinician work satisfaction. ${ }^{19-24}$

PACK has been localised to other LMICs-Mexico, Malawi, Botswana, The Gambia, Brazil, Nigeria, Ethiopia-and receives ongoing interest from many more. To service this interest and the in-country engagement, the KTU entered into a non-profit strategic partnership with the BMJ Publishing Group, drawing on BMJ's global footprint and operations and expertise in publishing, technology, communications and partnerships, with a shared vision to improve health and healthcare, focusing on areas of greatest need. The partnership also provided the mechanism to streamline localisation and maintenance of the PACK guide. Drawing on BMJ evidence synthesis product, Best Practice, the KTU created the 'PACK Global Adult' guide, where each of the over 2300 diagnostic, screening and management recommendations are informed by evidence and, to reflect an LMIC reality, are aligned to WHO guidance. This PACK Global guide serves as an up-to-date template for in-country localisation. Development of the PACK guide is described elsewhere. ${ }^{25}$

\section{DESCRIPTION AND COMPARISON OF IN-COUNTRY LOCALISATIONS}

The process of adapting the PACK programme and predecessor PALSA PLUS to other LMICs has evolved over the past 8 years. Figure 1 depicts the timeline for these localisations.

Once success of the programme in South Africa became known through research publications and as an example of the PAL strategy, ${ }^{26}$ pulmonologists from two countries

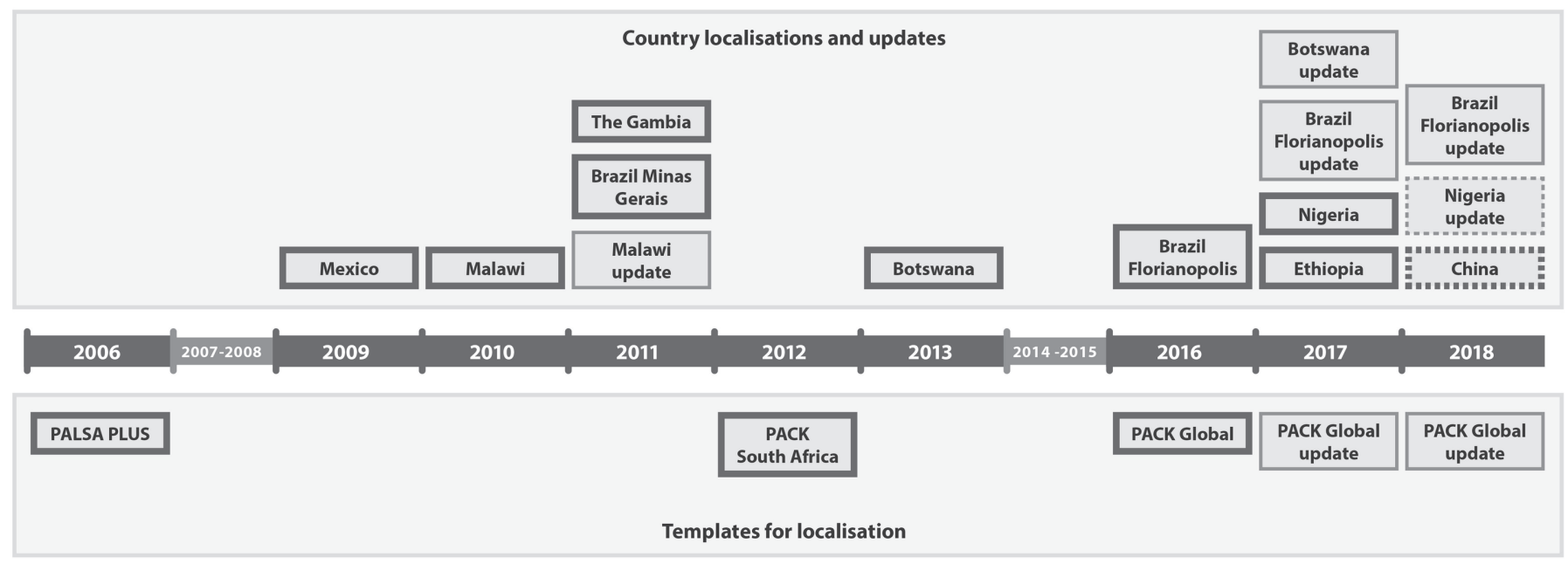

Figure 1 Timeline for in-country PALSA PLUS and Practical Approach to Care Kit (PACK) localisations. 
localised PALSA PLUS to their own setting independent of the KTU-Minas Gerais state, Brazil ${ }^{27}$ and Mexico. We called this approach an independent model of localisation as this work occurred without the involvement or subsequent evaluation by KTU.

Separately, the KTU embarked on localisation of first the PALSA PLUS programme in $\mathrm{Malawi}^{28}$ and then PACK in Botswana. ${ }^{29}$ During both localisations, the KTU Content team led localisation of guide content and interrogation of related health systems issues (like medication and test availability), and the Training team adapted the training material, delivered the first level of training and capacitated local partners to lead the programme with ongoing KTU training lead guidance. This we called a consultancy model of localisation as it relied on our unit leading and conducting the localisation process with support from local parties.

The Gambian Ministry of Health National TB Programme leads then approached the KTU to assist with localising and implementing PALSA PLUS. As we had no capacity to do so in the limited timeframe and budget, we deferred this consultancy to the programme manager from the NGO organisationwe had worked with on the Malawi localisation and implementation.

Following these experiences, we were reluctant to replicate such a consultancy model, because it was too resource intensive and time-consuming to be reproducible at scale. We were also concerned that this model did not create sufficient local ownership of the programme, potentially compromising scalability and sustainability.

Thus, when approached by a Brazilian team, we tried a mentorship model of localisation where the KTU team mentored in-country stakeholders to localise the programme and tackle the health systems issues that localisation surfaced. This 'letting go' of the process on the part of the English-speaking KTU team was also necessitated by the fact that the content, implementation and subsequent evaluation were in Brazilian Portuguese. The Brazil localisation is described in another paper in this Collection. ${ }^{30}$

We have since refined this mentorship model to support PACK localisations in Nigeria ${ }^{31}$ and Ethiopia, ${ }^{32}$ with some variation in response to local resources, timeframes and funding models.

The features of each in-country localisation are compared in table 1 .

\section{THE PACK MENTORSHIP MODEL OF LOCALISATION}

Figure 2 details a nine-step mentorship process that the KTU team (project manager and content and training team mentors) applied throughout the Brazil, Nigeria and Ethiopia localisation experiences. The steps comprise local engagement and introduction to the PACK programme, KTU mentorship of the in-country localisation of the guide, training programme and tackling of health systems issues, user testing, initial implementation and concurrent evaluation. Key to each step is an emphasis on applying the PACK principles and continuously engaging local stakeholders.

Before embarking on the localisation work, we invested time to introduce the teams to one another and to the elements of the PACK programme and the plan for mentorship, localisation and implementation. Visits by the localising teams to South Africa occurred to allow them to experience the programme first-hand.

Localising the guide, training materials and tackling health systems issues was an iterative process, with PACK Global guide content prompting interrogation of health systems issues, and clinical scenarios and health systems realities and priorities altering guide content. This made stakeholder input vital and end-user testing a key step. In Nigeria, for example, a questionnaire and consultation $\log$ that required end-users to work off priority guide pages, like 'cough and difficulty breathing' and 'HIV' helped to identify gaps and errors.

We borrowed agile development concepts from the information technology industry ${ }^{33}$ to make tackling comprehensive content more manageable. We divided guide content into sections for localisation, provided attentive project management and regarded the localised guide as 'Version 1' which allowed the teams to park lower priority content (like hair loss in Ethiopia) for future editions in order to maintain momentum of localisation and stakeholder engagement.

Thus far, the KTU has managed the artwork of the guide and most training materials. As some of the PACK guide's appeal is its design-full colour, carefully formatted algorithms and checklists, illustrations and photographs-design expertise and expensive graphic artwork programmes are needed to maintain its high quality. Localising teams have had neither the capacity nor resources to perform this function. It has also enabled the KTU content mentor to have 'sign-off' of all guide content.

At the outset, the in-country localising team received a PACK Manual for Localisation and Implementation with an accompanying Toolkit. The manual conveys PACK principles and gives step-by-step guidance for the localisation process. The toolkit contains the components of the programme- the PACK guide, lists of medication, equipment and tests and training materials-as well as the tools used for localisation and implementation: localisation schedule, evidence and decision support document for guide localisation (with references underpinning each guide recommendation), editable templates of guide and training programme and materials and printing specifications.

\section{CHALLENGES OF THE MENTORSHIP MODEL OF PACK LOCALISATION}

Each of the Brazil, Nigeria and Ethiopia PACK localisation mentorship experiences met challenges along the way. 


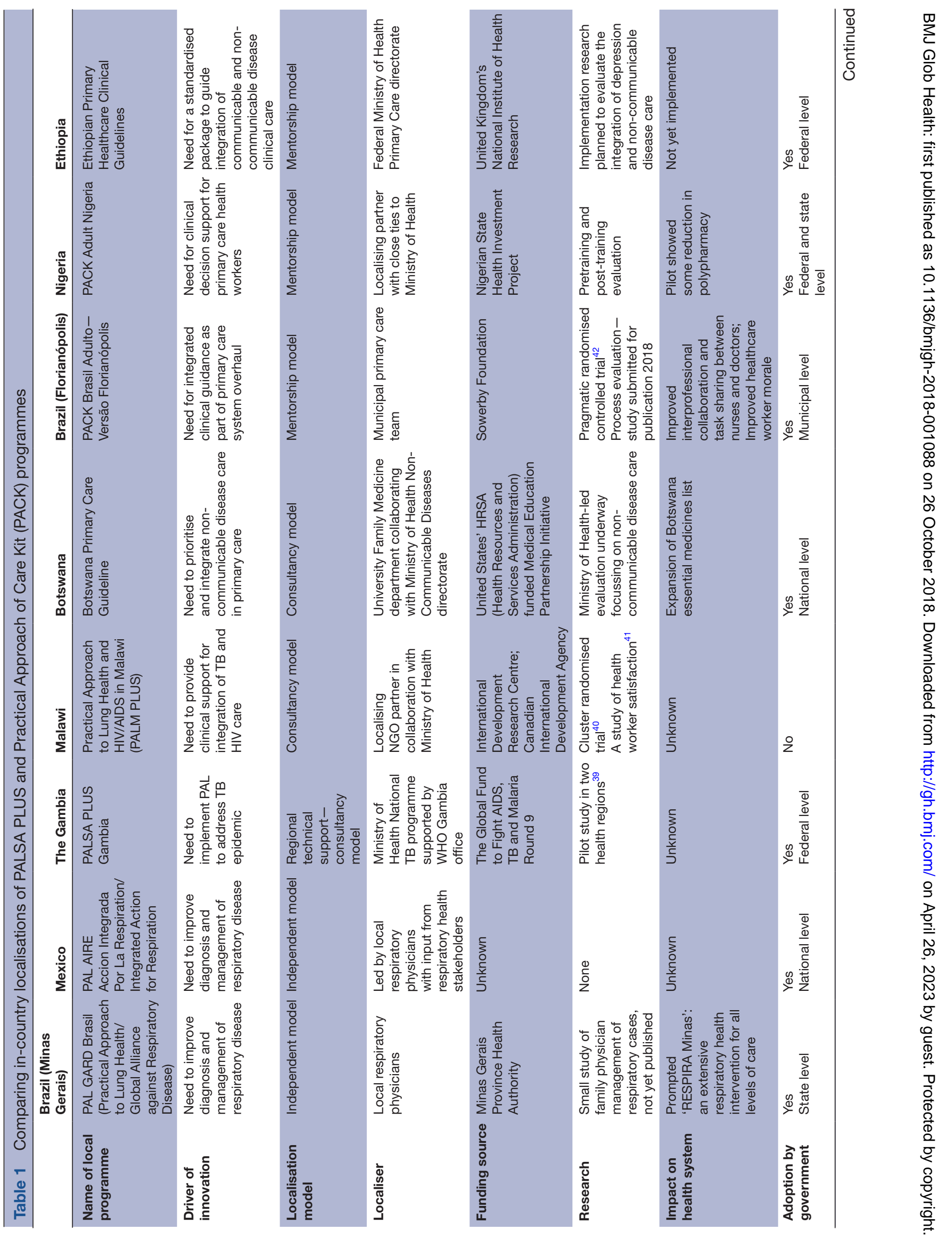




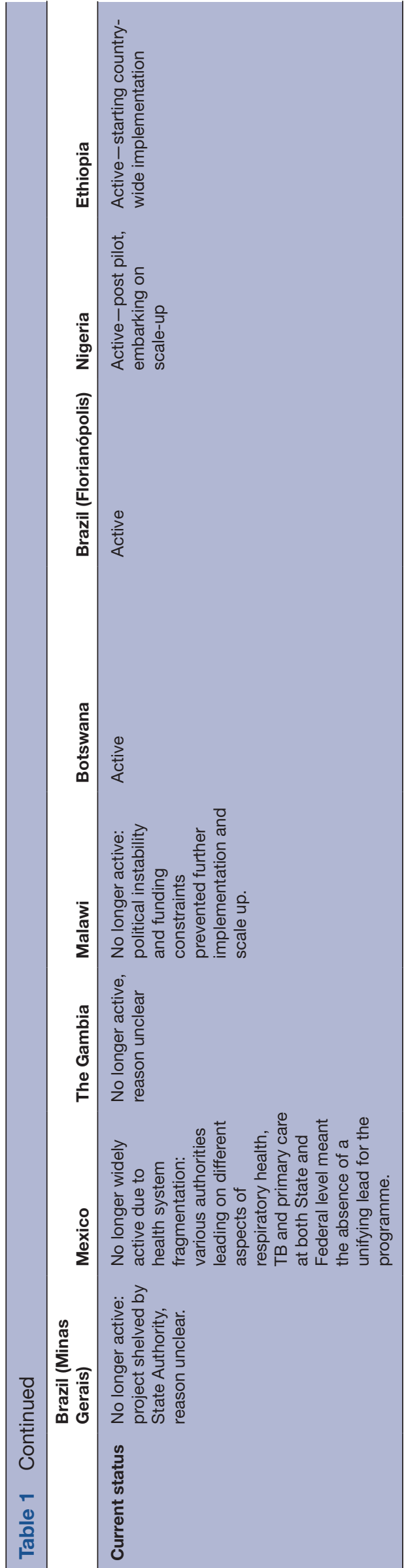

\section{Localising team availability was limited at times}

Except in Brazil where the localising team lead was relieved of other responsibilities, members of the localising teams had to fit PACK between ongoing work commitments. The Ethiopia team addressed this by convening 2-week intensive localisation workshops for local clinical experts who then took time out from their usual responsibilities; the Nigeria team scheduled regular late-afternoon meetings after the work day was done.

Communication and language differences could be frustrating Regular communication between the KTU mentors and localising teams in Nigeria and Ethiopia was often frustrated by poor internet and telephone connectivity. In Brazil, the language difference occasionally made communication difficult but was especially apparent in localising guide content where Brazilian Portuguese required more space than the English equivalent, necessitating careful editing.

\section{Conveying the PACK principles was challenging}

At times, localising teams lost sight of the PACK principles, attempting to add more content to the guide (overwhelming in both volume and layout) or speed up the delivery (which can undermine efforts to embed the programme into practice). Team visits helped to mitigate this, clarifying the principles when pages were workshopped together and localising teams experienced PACK in action during on-site training.

\section{Funding was limited}

PACK localisation is time intensive, requiring detailed attention from both teams. However, the costs of this work are often beyond government budgets, and local regulatory constraints make it difficult for governments to contract with and transfer funds to external organisations like the KTU and BMJ that do not have in-country operating entities. As a result, PACK localisations usually occur with minimal funding and extensive in-kind support from KTU, BMJ and localising partners. Thus, early implementation is slow and small, making it difficult to demonstrate the level of embeddedness in the health system and definitive positive outcomes to justify further roll-out. This is an experience not unique to PACK, ${ }^{6}$ but it has placed severe financial pressure on the soft-funded KTU.

\section{Political instability was disruptive}

Localisation and implementation were interrupted or slowed by country-wide political instability (Malawi, Brazil) and changes in health organisation structuring and leadership (Nigeria, Brazil, Ethiopia). This argues the case for acquiring both high level and on-the-ground buy-in for the programme that can then weather fluctuating political environments-demonstrated by PACK's survival in Florianópolis, Brazil.

\section{LESSONS LEARNT}

From our experience of supporting the localisation of PACK in a variety of LMIC settings, we have learnt lessons 
Step-by-step mentorship of PACK programme localisation and initial implementation

\section{Duration of Localisation and} each step

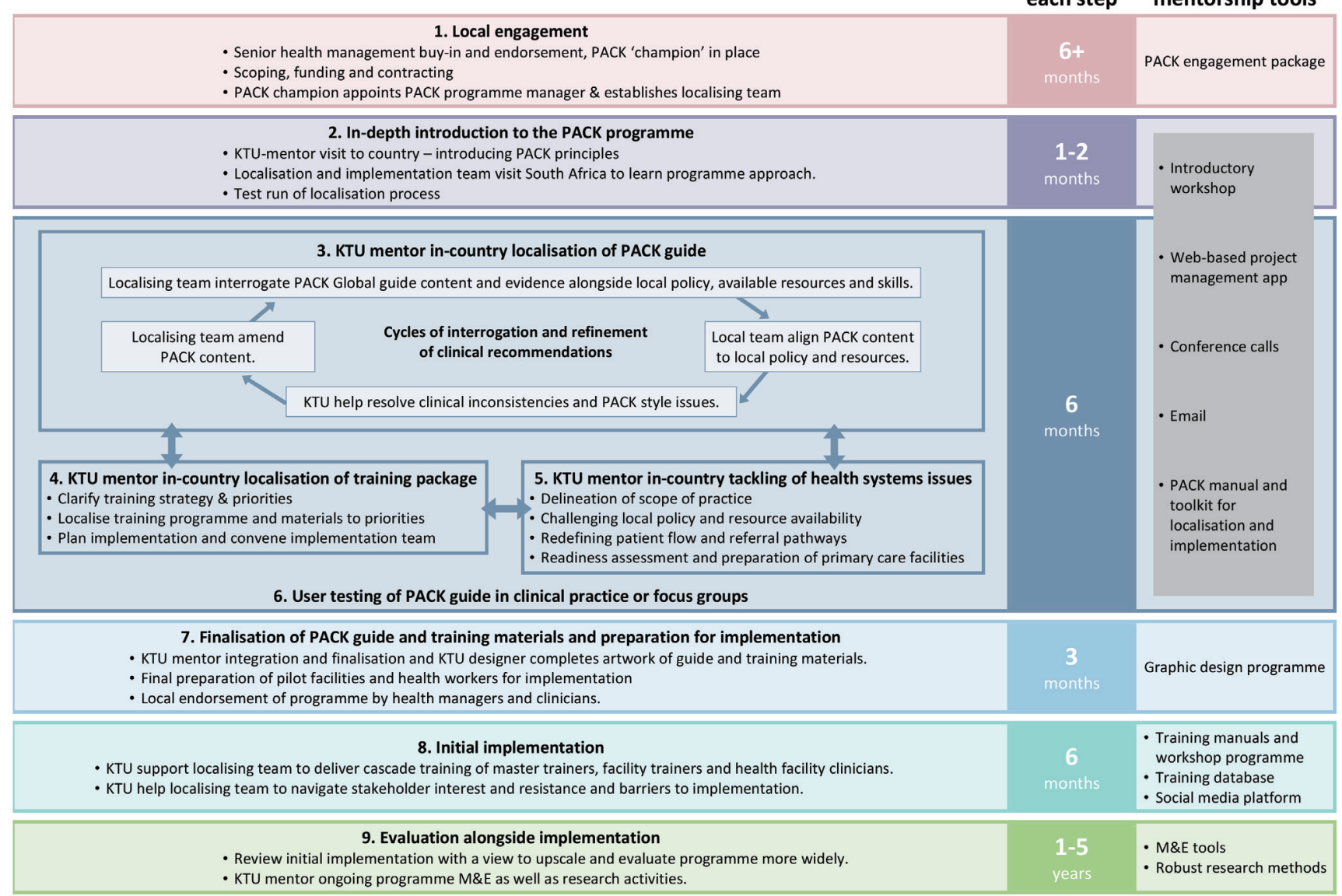

Figure 2 Step-by-step mentorship of PACK programme localisation and initial implementation. PACK, Primary Approach of Care Kit; KTU, Knowledge Translation Unit; M\&E, Monitoring and evaluation.

about both the localisation process and the mentorship of that process.

\section{Mentorship is a good model for localisation}

A mentorship approach to localisation appears to be a good and viable model. All three countries completed localisation successfully, Brazil and Nigeria have completed pilot implementation with plans for expansion and Ethiopia is set to embark on nationwide roll-out. Mentorship ensured quality assurance and adherence to the PACK principles. However, the process must be flexible, with each localisation adjusting the model as required: Brazil repackaged the modularised PACK training programme as ongoing sessions that focused on participant need, to expedite completion, Ethiopia conducted intensive localisation workshops rather than sticking to the PACK 4-month schedule and Nigeria is adding paediatric content in the Adult guide during its 2018 update.

\section{Achieving stakeholder buy-in is key}

To ensure successful localisation and then adoption of PACK, stakeholder buy-in has been key from the outset. Able clinicians in touch with on-the-ground realities but with the political capital to draw on relevant stakeholders need to lead programme localisation and implementation. Family physicians, often leaders in primary care, are ideally placed to do so and in each localisation played an important role. In Nigeria, end-user testing led to buy-in from both end-users and managers, and early engagement with both policy makers and pilot facilities ensured PACK Nigeria's successful implementation in all but one pilot facilities. $^{34}$

Although both PAL $^{35}$ and mhGAP ${ }^{36}$ implementation frameworks advise gaining high level government buy-in as a first step, in our experience, this has been difficult to achieve from the outset, and only once a pilot has showcased the programme and its potential has it generated national level interest.

\section{Regard localisation as the first step of implementation}

Shifting the perspective that localisation is a separate, preimplementation activity to one that is integral to implementation has both facilitated localisation and achieved stakeholder support. The Nigeria localisation saw the interrogation of policies, update of medicines lists, equipment and test availability and adjustments to scope of practice and referral pathways occurring in parallel with stakeholder engagement sessions, end-user 
testing and facility readiness preparations which meant the guide was completed in time and its uptake enthusiastic in pilot states.

Apply mentorship learnings from one localisation to the next Localisation prompted the development of setting-specific content for example, Chikungunya in Brazil, sickle cell anaemia in Nigeria. As these conditions are regional issues, we chose not to include them in the global guide and toolkit update but might draw on them if needed. However, some local changes were generic enough to be absorbed into the global update and then implemented in other localisations like tobacco cessation from Brazil and an expansion of palliative care guidance from Ethiopia, depicted in figure 3.

In addition to content innovations, there were instances where enhancements to the localisation process were then absorbed into the mentorship of other countries. Brazil introduced a project management app that has since supported each localisation and also identified the need to clearly explain the training approach, prompting expansion of the toolkit to include videos explaining the features and principles of the guide and training.

\section{Team visits are necessary and useful}

Face-to-face visits, while costly, have been vital to building KTU-localising team relationships. The visits provided the opportunity to workshop challenging localisation issues together and facilitated localising team participation in PACK training-experiencing the programme in action helped to adjust implementation plans and facilitated high fidelity to PACK principles.

\section{FUTURE DEVELOPMENTS Where next?}

We have decided to focus initial PACK expansion efforts on large LMICs in different regions of the world. This might allow us to recoup some of the investment in upfront localisation and piloting through wider in-country applicability and see whether emerging similarities hold true across diverse environments. Ultimately, we envisage PACK regional technical support hubs-for example, the Brazil team supporting Latin American localisations, Nigeria supporting West African. We shall prioritise LMICs over high-income countries, although recognise the potential of PACK in that setting ${ }^{37}$ given the need for cost reduction and inequalties in healthcare.

PACK continues to be spread with support from the KTU using an ever-evolving mentorship approach. The Peking University Family Medicine department has embarked on PACK localisation in China. Funding constraints and language barriers might limit mentorship, allowing us to examine successes and challenges of a relatively unsupported localisation and to enhance the PACK Localisation Manual and Toolkit.

\section{PACK global movement}

The PACK programme receives interest from leaders in both PACK-implementing and PACK-interested

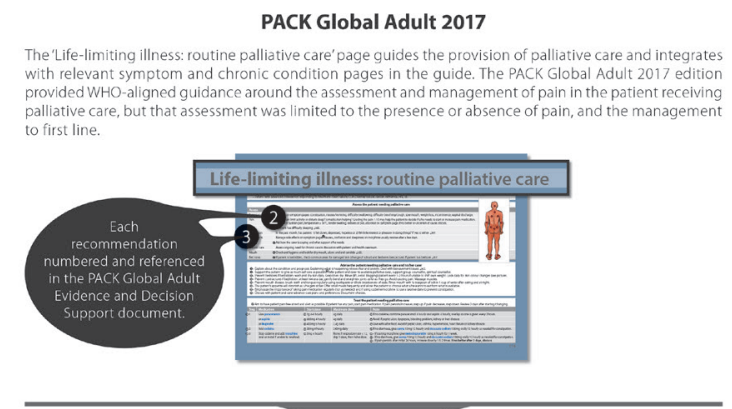

Figure 3 Applying learnings from one localisation to the next. 
countries, global health leaders, academic institutions, technical advisory organisations and healthcare providers and funders. The KTU and BMJ are launching a "PACK Global Movement" of PACK implementers and advocates that share experiences from PACK implementations and collaborate on evaluation activities. The movement could also create the impetus to achieve ongoing funding to sustain global and in-country PACK activities.

\section{Supporting in-country upscale and sustaining of PACK}

In 2017, the KTU supported the update of the PACK guide and training materials in Brazil and is currently mentoring the update and upscale of the programme in Nigeria (see the timeline in figure 1). Future work will include finalising a manual, toolkit and mentorship package for the update, upscale and sustaining of the programme in-country.

\section{Evaluation}

This practice paper is a description of the PACK localisation experiences, not a formal evaluation of the PACK approach to spread. We plan to formally evaluate how best to localise PACK in an effective way that ultimately needs minimal external support. First, using key role-player interviews, we need to deepen our understanding of the localisation experiences thus far, whether through an independent, consultancy or mentorship model. Evaluations of future localisations could include qualitative comparative case studies and pragmatic trials to examine outcomes like quality of guide localisation, effectiveness of the implementation strategy, acceptability of the programme among policymakers and health workers, its scalability and sustainability, and ultimately impact on quality of care. We also need to develop and evaluate different approaches for maintenance and in-country scale up, as local programmes mature. Such evaluations would contribute to the literature on localising and disseminating health systems interventions to LMIC settings.

\section{CONCLUSION}

The PACK localisation experience, though still in its infancy, has thus far been successful in several LMICs. Crucial throughout has been balancing the PACK principles with a degree of local reinvention, addressing health system strengthening and involving local stakeholders. Ultimately, PACK has been championed by local clinicians with an understanding of and a strong vision for integrated primary care.

Using a mentorship model to support in-country localisation has been feasible within the limited resources of our team and allowed for the iterative improvement of both the model and the PACK programme from one localisation experience to the next-a learning health system ${ }^{38}$ with global reach. The lessons that have emerged have helped to craft a viable model for taking
PACK to other countries that now requires formal evaluation to test for its effectiveness and reproducibility across borders. Such evaluations could also contribute to an understanding of how different models for spreading health systems innovations work.

Acknowledgements We acknowledge all those who supported and conducted localisations of PACK, in particular, Matheus De Andrade and Ronaldo Zonta who led the Brazil localisation, Joseph Ana who led the Nigeria localisation and Yibeltal Mekonnen who led the Ethiopia localisation. We acknowledge the in-kind contribution from the Health Department of the Municipality of Florianopolis for the PACK Brazil localisation.

Contributors RC wrote the first draft of the paper. All authors contributed intellectual content, edited the manuscript and approved the final version for submission.

Funding The KTU has received funding from various sources for PALSA PLUS and PACK localisation support work. The International Development Research Centre (IDRC) and Canadian International Development Agency (CIDA) funded work in Malawi and the Medical Education Partnership Initiative (MEPI) supported the PACK Botswana localisation, specifically funded by US' HRSA (Health Resources \& Services Administration). The PACK Nigeria pilot was funded through the Nigerian State Health Investment Project (NSHIP), a World Bank-assisted initiative led by Nigeria's National Primary Health Care Development Agency. The localisation of the PACK Nigeria guide and training resources was funded through a central NSHIP technical assistance budget managed by Oxford Policy Management. The KTU mentorship of the Ethiopian localisation work was supported by the United Kingdom's National Institute of Health Research (NIHR) using Official Development Assistance (ODA) funding (NIHR Global Health Research Unit on Health System Strengthening in Sub-Saharan Africa, King's College London (16/136/54)). The KTU received funding to support the development of the PACK localisation package from the Peter Sowerby Charitable Foundation. Additional funding was provided by the BMJ Publishing Group and University of Cape Town Lung Institute. Tanya Doherty's time was supported by the South African Medical Research Council. PACK receives no funding from the pharmaceutical industry.

Disclaimer The views expressed in this publication are those of the author(s) and not necessarily those of the NHS, the National Institute for Health Research or the English Department of Health.

Competing interests We have read and understood BMJ policy on declaration of interests and declare that RC, CW, AA, CR, LA, EB and LF are employees of the KTU. T Eastman is a contractor for both KTU and BMJ, London, UK. JZ is an ex-employee of the City Health Department, Florianópolis, Brazil and a current holder of full-time $\mathrm{PhD}$ studentship from the Brazilian research agency CNPq. MZ is an employee of the Centre for Studies in Family Medicine, Schulich School of Medicine \& Dentistry, Western University, London, Ontario, Canada. TD is an employee of the South African Medical Research Council. EB reports personal fees from ICON, Novartis, Cipla, Vectura, Cipla, Menarini, ALK, ICON, Sanofi Regeneron, Boehringer Ingelheim and AstraZeneca, and grants for clinical trials from Novartis, Boehringer Ingelheim, Merck, Takeda, GlaxoSmithKline, Hoffmann le Roche, Actelion, Chiesi, Sanofi-

Aventis, Cephalon, TEVA and AstraZeneca. All of EB's fees and clinical trials are for work outside the submitted work. EB is also a Member of Global Initiative for Asthma Board and Science Committee. Since August 2015 the KTU and BMJ have been engaged in a non-profit strategic partnership to provide continuous evidence updates for PACK, expand PACK related supported services to countries and organisations as requested, and where appropriate license PACK content. The KTU and BMJ co-fund core positions, including a PACK Global Development Director, and receive no profits from the partnership. PACK receives no funding from the pharmaceutical industry. This paper forms part of a Collection on PACK sponsored by the BMJ to profile the contribution of PACK across several countries towards the realisation of comprehensive primary health care as envisaged in the Declaration of Alma Ata, during its 40th anniversary.

Patient consent Not required.

Provenance and peer review Not commissioned; externally peer reviewed.

Data sharing statement № additional data are available.

Open access This is an open access article distributed in accordance with the Creative Commons Attribution Non Commercial (CC BY-NC 4.0) license, which permits others to distribute, remix, adapt, build upon this work non-commercially, and license their derivative works on different terms, provided the original work is properly cited, appropriate credit is given, 
any changes made indicated, and the use is non-commercial. See: http:// creativecommons.org/licenses/by-nc/4.0

\section{REFERENCES}

1. Primary Health Care Performance Initiative, 2018. Promising practices' website. Available from: https://phcperformanceinitiative. org/tools/promising-practices [accessed Jul 2018].

2. World Health Organisation, 2018. Maternal, newborn, child and adolescent health. Available from: http://www.who.int/maternal_ child_adolescent/topics/child/imci/en/ [accessed Jul 2018].

3. World Health Organisation, 2016. mhGAP Intervention guide version 2.0 for mental, neurological and substance use disorders in non- specialized health settings. Available from: http://www.who.int/ mental health/mhgap/mhGAP intervention guide 02/en/

4. World Health Organisation, 2018. Practical Approach to Lung Health (PAL). Available from: http://www.who.int/tb/health systems/pal/en/ [accessed Jun 2018].

5. Vasan A, Ellner A, Lawn SD, et al. Strengthening of primary-care delivery in the developing world: IMAI and the need for integrated models of care. Lancet Glob Health 2013;1:e321-3.

6. World Health Organisation Report, 2008. Evaluation of the Practical Approach to Lung Health Report of meeting held on 18 and 19 June 2007. WHO, Geneva, stop TB department. 2008. Available from: http://apps.who.int/iris/bitstream/handle/10665/69730/WHO_HTM_ TB_2008.396_eng.pdf;jsessionid=AA79EA73E19EE27F3804CE3D EAË50C87? sequence $=1$

7. Chopra M, Binkin NJ, Mason E, et al. Integrated management of childhood illness: what have we learned and how can it be improved? Arch Dis Child 2012;97:350-4.

8. Fervers B, Burgers JS, Voellinger R, et al. Guideline adaptation: an approach to enhance efficiency in guideline development and improve utilisation. BMJ Qual Saf 2011;20:228-36.

9. Gonzalez-Suarez CB, Grimmer-Somers K, Dizon J, et al. Contextualizing Western guidelines for stroke and low back pain to a developing country (Philippines): an innovative approach to putting evidence into practice efficiently. J Healthc Leadersh 2012;2012:141-56.

10. Oxman $A D$, Fretheim $A$, Schünemann $H J$, et al. Improving the use of research evidence in guideline development: introduction. Health Res Policy Syst 2006;4:12.

11. Dizon JM, Grimmer K, Louw Q, et al. South African Guidelines Excellence (SAGE): adopt, adapt, or contextualise? S Afr Med J 2016;106:1177-8.

12. Schünemann $\mathrm{HJ}$, Wiercioch W, Brozek J, et al. GRADE Evidence to Decision (EtD) frameworks for adoption, adaptation, and de novo development of trustworthy recommendations: grade-adolopment. J Clin Epidemiol 2017;81:101-10.

13. Wang Z, Norris SL, Bero L. The advantages and limitations of guideline adaptation frameworks. Implement Sci 2018;13:72

14. World Health Organisation, 2010. Nine steps for developing a scaling-up strategy. Available from: http://www.who.int/ immunization/hpv/deliver/nine_steps_for_developing_a_scalingup strategy_who_2010.pdf [accessed June 2018]

15. Bradley E, Curry L, Pérez-Escamilla R, et al. 2011. Dissemination, diffusion and scale up of family health innovations in low-income countries 2011 report. Available from: https://docs.gatesfoundation. org/documents/yale-global-health-report.PDF

16. Georgeu-Pepper D, Fairall F, Bateman E, et al. Translating knowledge into practice: core principles of the Practical Approach to Care Kit. To be submitted to BMJ Global Health as part of the PACK Collection.

17. Simelane M, Georgeu-Pepper D, Ras CJ. The Practical Approach to Care Kit (PACK) training programme - scaling up and sustaining support for health workers to improve primary care. BMJ Global Health 2018; In press. doi: 10.1136/bmjgh-2018-001124.

18. South Africa National Department of Health Ideal Clinic Website. Available from: https://www.idealclinic.org.za/

19. Fairall LR, Zwarenstein M, Bateman ED, et al. Effect of educational outreach to nurses on tuberculosis case detection and primary care of respiratory illness: pragmatic cluster randomised controlled trial. BMJ 2005;331:750-4.

20. Zwarenstein M, Fairall LR, Lombard C, et al. Outreach education for integration of HIV/AIDS care, antiretroviral treatment, and tuberculosis care in primary care clinics in South Africa: PALSA PLUS pragmatic cluster randomised trial. BMJ 2011;342:d2022.

21. Fairall L, Bachmann MO, Lombard C, et al. Task shifting of antiretroviral treatment from doctors to primary-care nurses in South
Africa (STRETCH): a pragmatic, parallel, cluster-randomised trial Lancet 2012;380:889-98.

22. Fairall LR, Folb N, Timmerman V, et al. Educational outreach with an integrated clinical tool for nurse-led non-communicable chronic disease management in primary care in South Africa: a pragmatic cluster randomised controlled trial. PLoS Med 2016;13:e1002178.

23. Stein J, Lewin S, Fairall L, et al. Building capacity for antiretroviral delivery in South Africa: a qualitative evaluation of the PALSA PLUS nurse training programme. BMC Health Serv Res 2008;8:240.

24. Georgeu D, Colvin CJ, Lewin S, et al. Implementing nurse-initiated and managed antiretroviral treatment (NIMART) in South Africa: a qualitative process evaluation of the STRETCH trial. Implement Sci 2012;7:66.

25. Cornick R, Picken S, Wattrus C, et al. The Practical Approach to Care Kit (PACK) guide: developing a clinical decision support tool to simplify, standardise and strengthen primary healthcare delivery. BMJ Glob Health 2018;3(Suppl 5):e000962.

26. Demonstration project, 2018. Global Alliance against Chronic Respiratory Disease website - Demonstration project. Available from: http://www.who.int/gard/countries/demonstration_project south_africa/en/ [accessed Jun 2018].

27. Cruz AA, Camargos PA, Urrutia-Pereira M, et al. Global Alliance against Chronic Respiratory Diseases (GARD) Brazil success case: overcoming barriers. J Thorac Dis 2018;10:534-8.

28. Schull MJ, Cornick R, Thompson S, et al. From PALSA PLUS to PALM PLUS: adapting and developing a South African guideline and training intervention to better integrate HIV/AIDS care with primary care in rural health centers in Malawi. Implement Sci 2011;6:82.

29. Tsima BM, Setlhare V, Nkomazana O. Developing the Botswana Primary Care Guideline: an integrated, symptom-based primary care guideline for the adult patient in a resource-limited setting. $J$ Multidiscip Healthc 2016:9:347-54.

30. Wattrus C, Zepeda J, Cornick R, et al. Using a mentorship model to localise the Practical Approach to Care Kit (PACK): from South Africa to Brazil. BMJ Glob Health 2018. In press: doi: 10.1136/ bmjgh-2018-001016.

31. Awotiwon A, Sword C, Eastman T, et al. Using a mentorship mode to localise the Practical Approach to Care Kit (PACK): from South Africa to Nigeria. BMJ Global Health 2018;3(Suppl 5):e001079.

32. Mekonnen $Y$, Hanlon C, Ferede S, et al. Using a mentorship model to localise the Practical Approach to Care Kit (PACK): from South Africa to Ethiopia. BMJ Glob Health 2018. In press: doi: 10.1136/ bmjgh-2018-001108.

33. Flood D, Chary A, Austad K, et al. Insights into Global Health Practice from the Agile Software Development Movement. Glob Health Action 2016;9:29836.

34. Ana J, Sword C. Final Report on PACK Nigeria Adult Pilot Version 1.2. 26 October 20172017.

35. World Health Organization. Practical Approach to Lung Health Manual on Initiating PAL Implementation. Geneva: World Health Organization, 2008.

36. mhGAP World Health Organisation, 2008. Mental Health Gap Action Programme: Scaling Up Care for Mental, Neurological and Substance Use Disorders. Available from: https://www.ncbi.nlm.nih. gov/books/NBK310850/

37. Depasse JW, Lee PT. A model for 'reverse innovation' in health care. Global Health 2013;9:40.

38. Sheikh K, Schneider H, Agyepong IA, et al. Boundary-spanning: reflections on the practices and principles of Global Health. BMJ Glob Health 2016;1:e000058.

39. World Health Organisation Health, 2018. World Health Organisation Health Situation Analysis The Gambia webpage. Available from: http://www.aho.afro.who.int/profiles_information/index.php/Gambia: Analytical summary - Tuberculosis [accessed May 2018].

40. Sodhi S, Banda H, Kathyola D, et al. Evaluating a streamlined clinica tool and educational outreach intervention for health care workers in Malawi: the PALM PLUS case study. BMC Int Health Hum Rights 2011;11:.S11.

41. Sodhi S, Banda H, Kathyola D, et al. Supporting middle-cadre health care workers in Malawi: lessons learned during implementation of the PALM PLUS package. BMC Health Serv Res 2014;14(Supp 1):S8.

42. Bachmann MO, Bateman ED, Stelmach R. Integrating primary care of chronic respiratory disease, cardiovascular disease and diabetes in Brazil: practical approach to care kit (pack brazil): study protocol for randomised controlled trialsPractical Approach to Care Kit (PACK Brazil): study protocol for randomised controlled trials. J Thorac Dis 2018;10:4667-77. 